\title{
Uklanjanje bojila iz tekstilne otpadne vode ultrafiltracijskim membranama
}

\author{
1. Ćurić, ${ }^{a}$ D. Dolar ${ }^{\text {b* }}$ i K. Karadakićb \\ a Galeb dalmatinska trikotaža d. d., Punta 6, 21310 Omiš, Republika Hrvatska \\ b Sveučilište u Zagrebu, Fakultet kemijskog inženjerstva i tehnologije, \\ Marulićev trg 19, 10000 Zagreb, Republika Hrvatska
}

https://doi.org/10.15255/KUI.2020.034

KUI-50/2020

Izvorni znanstveni rad

Prispjelo 8. svibnja 2020.

Prihvaćeno 15. lipnja 2020.

Ovo djelo je dano na korištenje pod Creative Commons Attribution 4.0

International License

\begin{abstract}
Sažetak
Otpadne vode tekstilne industrije pripadaju kategoriji najjače onečišćenih industrijskih otpadnih voda te su posebna opasnost za vodeni okoliš. Cilj ovog istraživanja bio je ispitati membransku učinkovitost zadržavanja bojila iz tekstilne otpadne vode (TOV) s komercijalnim ultrafiltracijskim (UF) membranama (GH, GK, PT, PU, PW, MW) širokog područja graničnih molekulskih masa (MWCO), od 2 do 50 kDa. Testirane UF membrane rezultirale su smanjenjem obojenja i intenziteta obojenja od 56,35 \% do $97,93 \%$. Membrane nižih MWCO vrijednosti (ispod $3 \mathrm{kDa}$ ) mogu se smatrati prikladnim za uklanjanje bojila iz realnog uzorka TOV-a.
\end{abstract}

\section{Ključne riječi}

Tekstilna industrija, otpadna voda, ultrafiltracija, boja, bojila

\section{Uvod}

Tekstilna industrija jedna je od zahtjevnijih prerađivačkih industrija zbog svoje fragmentirane i heterogene strukture, počevši od proizvodnje sirovine (sintetske ili prirodne) do poluproizvoda (pletivo, tkanina) i gotovog proizvoda. ${ }^{1,2}$ Unutar tehnološkog postupka proizvodnje postoji tzv. mokra dorada u kojoj se odvijaju procesi predobrade, bojadisanja, oplemenjivanja i tiskanja. ${ }^{3}$ Takve vrste procesa zahtijevaju upotrebu bojila, pomoćnih tekstilnih sredstava i velikih količina vode. ${ }^{4}$ Količina vode ovisi o vrsti tekstila koji se proizvodi, vrsti upotrijebljenih bojila i proizvodnim sekvencama. ${ }^{5}$ Prema podatcima Američke agencije za zaštitu okoliša (EPA) za proizvodnju 9072 kg tekstila potroši se 36000 I vode. ${ }^{6}$ Od ukupno upotrijebljene vode u procesu proizvodnje čak $90 \%$ na kraju završi kao otpadna voda u kojoj su bojila prisutna u koncentracijama od 10 do $50 \mathrm{mgl}^{-1} .7 \mathrm{U}$ prosjeku 10 - $15 \%$ bojila odlazi u otpadnu vodu tijekom procesa bojadisanja, ${ }^{8}$ a čak pri koncentracijama većim od $1 \mathrm{mgl}^{-1}$ otopljena bojila postaju vidljiva u vodi (obojenje) i kao takva predstavljaju spojeve visoke stabilnosti, otporne na djelovanje svjetlosti, detergenata i drugih kemikalija. ${ }^{9}$ Otpadne vode tekstilne industrije stoga pripadaju kategoriji najjače onečišćenih industrijskih otpadnih voda te su ozbiljna opasnost za vodeni okoliš u koji se još uvijek ispuštaju bez odgovarajuće obrade. ${ }^{10}$
Sukladno navedenom, pronalazak učinkovite, praktične i pouzdane metode za uklanjanje bojila iz tekstilnih otpadnih voda (TOV) može smanjiti negativan utjecaj na vodeni okoliš, a posljedično tome i na čovjekovo zdravlje. ${ }^{6,11,12}$ Najčešće primijenjene metode za uklanjanje bojila iz TOV-a su konvencionalne metode: flokulacija, ${ }^{13,14}$ koagulacija, ${ }^{15,16}$ razgradnja $\mathrm{S}$ aktivnim muljem, ${ }^{17,18}$ aerobna/anaerobna razgradnja ${ }^{19,20}$ i elektroliza. ${ }^{21,22}$ Konvencionalne metode imaju nedostatke poput stvaranja velike količine mulja, nisku biorazgradivost nekih bojila, velika početna investiranja, stvaranje nusprodukata, dugo vrijeme obrade, itd. ${ }^{23} \mathrm{Uz}$ sve navedeno takve metode su skupe, a zbog varijabilnosti sastava otpadnih voda učinkovitost im je upitna. ${ }^{24}$

Napredni separacijski procesi sve više zamjenjuju konvencionalne metode obrade tekstilnih otpadnih voda zbog velike sposobnosti separacije i širokog spektra primjene u raznim područjima. ${ }^{25}$ Među najučinkovitije separacijske procese spadaju membranski procesi reverzne osmoze (RO) i nanofiltracije (NF), u kombinaciji s operacijama ultrafiltracije (UF) i mikrofiltracije (MF) za ublažavanje fenomena blokiranja i u posljednje vrijeme sve se više proučavaju za uklanjanje bojila iz tekstilne otpadne vode. ${ }^{25} \mathrm{RO} / \mathrm{NF}$ recentna istraživanja obrade tekstilne otpadne vode i uklanjanje bojila iz njih ukazuju na izraženo blokiranje i stvaranje "kolača" na NF i RO membranama. ${ }^{26-29}$ Posljedice blokiranja membrana su smanjenje radnog vijeka membrane, niža kvaliteta

\footnotetext{
*Autor za dopisivanje: izv. prof. dr. sc. Davor Dolar e-pošta:dolar@fkit.hr
} 
permeata i povećanje operativnih troškova. ${ }^{30} \mathrm{U}$ svrhu smanjenja navedenih problema $u$ radu $s$ RO/NF membranama poželjan korak predobrade je membranski postupak ultrafiltracije..$^{31,32}$

U svojem istraživanju Fersi $i$ Dhahbi ${ }^{33}$ usporedili su uklanjanje bojila iz tekstilne otpadne vode NF membranom i kombinacijom UF/NF membrana, pri čemu je UF membrana služila za predobradu u svrhu smanjenja blokiranja NF membrane. Utvrdili su da je primjenom NF membrane faktor zadržavanja bojila oko $90 \%$, dok kombinacijom UF/NF doseže do $99 \%$.

Uklanjanje sintetskih bojila (Everzol Blue, Everzol Red, Everzol Black) UF membranama iz tekstilne otpadne vode ispitali su Auoni i sur. ${ }^{34}$ Everzol Blue i Everzol Red bojilo u potpunosti je uklonjeno s UF membranom od $1 \mathrm{kDa}$. Faktor zadržavanja za bojilo Everzol Black iznosi 15 \% s UF membranom od $10 \mathrm{kDa}$, dok primjenom membrane od 1 kDa faktor zadržavanja nije bio veći od 80 \% čak ni pri povećanju radnog tlaka. Takav rezultat može se pripisati prostornoj konfiguraciji bojila Everzol Black. Berradi $i$ sur. ${ }^{35}$ uklanjali su sintetska bojila (Indigo i Sulphur Black) iz dviju različitih modelnih otopina $s$ UF polisulfonskom membranom. Faktor zadržavanja za Indigo bojilo bilo je 80,36 \%, dok za Sulphur Black 60,78 \%. Razlika između dobivenih vrijednosti pripisana je razlici u otopinama, pri čemu je propuštanjem otopine sa Sulphur Blackom došlo do blokiranja membrane. Sristava $i$ sur. $^{36}$ ispitali su mogućnost uklanjanja bojila $s$ modificiranom (poli(viniliden fluorid) i stiren-akrilonitril) UF membranom iz tekstilne otpadne vode. Ta je membrana uklonila $97 \%$ Congo Reda i više od 70 \% bojila Reactive Black 5 iz ulazne otopine. Ratanatamskul i Kaweenantawong ${ }^{37}$ uspješno su iz tri vrste otpadnih voda, koje se razlikuju po različitim vrstama bojila (reduktivna, direktna i disperzna), uklonili boju u iznosu od $96 \%$ do $100 \%$ s UF membranama.

Prethodno objavljeni radovi uglavnom su fokusirani na uklanjanje bojila s UF membranama iz modelnih tekstilnih otpadnih voda. ${ }^{34,38,39}$ No uklanjanje bojila iz realne tekstilne otpadne vode je neistraženo s obzirom na to da ona u svojem sastavu ima velik broj bojila nepoznatih koncentracija. Cilj ovog istraživanja bio je istražiti učinkovitosti uklanjanja bojila iz realne tekstilne otpadne vode s različitim UF membranama u obliku ravnih plahta čije su granične molekulske mase MWCO) u rasponu od 2 do $50 \mathrm{kDa}$. Prisutnost bojila u otpadnoj vodi te u struji permeata pratila su se mjerenjem obojenja $i$ intenziteta obojenja. Tijekom obrade TOV-a pratio se protok u svrhu praćenja blokiranja ispitivanih membrana.

\section{Eksperimentalni dio}

Tekstilna otpadna voda obrađena je komercijalnim UF membranama. Voda je uzorkovana iz egalizacijskog bazena tekstilne tvrtke Galeb d.d., Omiš, čija je osnovna djelatnost proizvodnja trikotažnih odjevnih predmeta uglavnom baziranih na prirodnim vlaknima (pamuk). Proces proizvodnje sastoji se od četiri glavna procesa: pletenje, dorada pletiva (bojadisanje, bijeljenje, pranje i sušenje), krojenje i šivanje, nakon čega slijedi završna faza, koja obuhvaća kontrolu i pakiranje. TOV se sastoji od reaktivnih bojila koja se najčešće upotrebljavaju za bojadisanje pamuka. Osim reaktivnih bojila, također su prisutna pomoćna tekstilna sredstva za potapanje, fiksiranje, odpjenjivači i dr. kao i kemikalije poput octene kiseline $\mathrm{i}$ natrijeva hidroksida. Uzorci su sakupljeni u nekoliko plastičnih posuda od $25 \mathrm{I}$ i dopremljeni u laboratorij, gdje su pohranjeni na temperaturi nižoj od $10{ }^{\circ} \mathrm{C}$ i upotrijebljeni unutar tri tjedna.

\subsection{Membrane}

Za obradu TOV-a upotrijebljeno je šest različitih komercijalnih UF membrana (GH, GK, PT, PU, PW i MW) u obliku. Dobavljene su od proizvođača GE Water \& Process Technologies (Nizozemska) te pohranjene na hladnom i tamnom mjestu (hladnjak) do njihove upotrebe. Nazivne karakteristike membrana definirao je proizvođač $i$ navedene su u tablici 1.

\subsection{Membranski uređaj}

Tekstilna otpadna voda obrađena je u laboratorijskom uređaju s ćelijom s ukriženim tokom, pumpom i izmjenjivačem topline koji je detaljno opisan u Racar $i$ sur. ${ }^{40}$ Površine membrana iznosile su $138 \mathrm{~cm}^{2}$. TOV (10 l) cirkulirao je kroz membransku jedinicu brzinom strujanja $0,75 \mathrm{~m} \mathrm{~s}^{-1}$ pri konstantnoj temperaturi od $25,0{ }^{\circ} \mathrm{C} \pm 0,1^{\circ} \mathrm{C}$. Radni tlak za GH membranu iznosio je 10 bar, a za GK 5 bar. PT membrana ispitivana je pri tlaku od 4 bar, PU i PW pri 2 bar, a MW pri 1,5 bar. Svi pokusi odrađeni su uz potpunu recirkulaciju permeata i retentata, što znači da su se permeat i retentat vraćali u spremnik ulazne otopine.

Prije pokusa s realnim uzorkom TOV-a nove membrane su isprane s $5 \mathrm{I}$ demineralizirane vode kako bi se uklonio konzervans. Uslijedila je stabilizacije protoka pojedinačnih membrana pri radnom tlaku. U sljedećem koraku obrađivan je TOV u trajanju od $3 \mathrm{~h}$ nakon čega je uzorkovan permeat $\mathrm{i}$ analiziran. Završna faza bila je ispiranje membrane $s$ demineraliziranom vodom u trajanju od $30 \mathrm{~min}$. U svim fazama protok je praćen mjerenjem mase u jedinici vremena svakih $10 \mathrm{~s}$ pomoću tehničke vage KERN 440-35A (Njemačka). 
Tablica 1 - Nazivne karakteristike ispitivanih UF membrana

Table 1 - Nominal characteristics of investigated UF membranes

\begin{tabular}{|c|c|c|c|c|c|}
\hline Membrana & Kemijski sastav & $\mathrm{MWCO} / \mathrm{kDa}$ & Maksimalni radni tlak/bar & Dopuštena pH vrijednost & Tipičan fluks / tlak $\mathrm{LMH}^{\mathrm{d}}$ / bar \\
\hline $\mathrm{GH}$ & $\mathrm{PA}^{\mathrm{a}}$ & 2 & 27 & $1-11$ & $34,0 / 10,3$ \\
\hline GK & $\mathrm{PA}^{\mathrm{a}}$ & 3 & 27 & $1-11$ & $28,9 / 5,17$ \\
\hline PT & $\mathrm{PES} / \mathrm{PS} f^{\mathrm{b}}$ & 5 & 10 & $1-11$ & $153 / 3,45$ \\
\hline PU & $\mathrm{PES} / \mathrm{PS} f^{\mathrm{b}}$ & 10 & 10 & $1-11$ & $144 / 2,07$ \\
\hline PW & $\mathrm{PES} / \mathrm{PS} \mathrm{f}^{\mathrm{b}}$ & 20 & 10 & $1-11$ & $144 / 2,07$ \\
\hline MW & $\mathrm{PES} / \mathrm{PSf} \mathrm{f}^{\mathrm{b}}$ & 50 & 7 & $2-9$ & $299 / 1,32$ \\
\hline
\end{tabular}

${ }^{a}$ - poliamid; ${ }^{b}$ - polieter(sulfon)/polisulfon; ${ }^{c}$ - poliakrilonitril; ${ }^{\mathrm{d}}-\mathrm{Im}^{-2} \mathrm{~h}^{-1}$

\subsection{Analiza vode i membrana}

Obojenje i intenzitet obojenja TOV-a i permeata analizirani su sa spektrofotometrom Hach Lange DR3900 (Njemačka). Obojenje je određeno prema ISO 7887: 1994 normi primjenom viševalne metode pri tri valne duljine i izračunato prema jedn. (1):

$$
\text { obojenje }=\frac{A_{(436 \mathrm{~nm})}^{2}+A_{(525 \mathrm{~nm})}^{2}+A_{(620 \mathrm{~nm})}^{2}}{A_{(436 \mathrm{~nm})}+A_{(525 \mathrm{~nm})}+A_{(620 \mathrm{~nm})}}
$$

gdje je $A$ apsorbancija mjerena pri valnoj duljini od $436 \mathrm{~nm}$, $525 \mathrm{~nm}$ i $620 \mathrm{~nm}$. Intenzitet obojenja dobiven je integracijom apsorpcijske krivulje $u$ mjernom rasponu između 340 i $900 \mathrm{~nm}$.

\section{Rezultati i rasprava}

\subsection{Uklanjanje obojenja i intenziteta obojenja s UF membranama iz TOV-a}

Uzorci TOV-a i permeata nakon $3 \mathrm{~h}$ obrade spektrofotometrijski su analizirani pri apsorbancijama od 436, 525 i $620 \mathrm{~nm}$ te je utvrđeno njihovo obojenje i intenzitet obojenja. Rezultati prikazani u tablici 2 pokazuju da su se vrijednosti obojenja u TOV-u kretale od 0,156 do 0,234, dok u permeatu nakon $3 \mathrm{~h}$ od 0,00594 do 0,0887. S obzirom na dobivene vrijednosti obojenja, smanjenje se kreće od 61,60 \% do 97,03 \% i prikazani su na slikama 1 i 2. Najbolje uklanjanje obojenja dobiveno je s $\mathrm{GH}$ membranom i iznosilo je 97,03 \%, dok je s GK membranom 84,05\%. Ostale membrane pokazuju smanjenje od $61,60 \%$ do $77,38 \%$. U istoj tablici prikazani su intenziteti obojenja TOVa i permeata svih membrana nakon 3 h obrade. Uzorci TOVa imali su intenzitet obojenja u rasponu od 77,39 do 107,4 te su nakon obrade UF membranama smanjeni na vrijednosti od 1,928 do 33,78. Smanjenja intenziteta obojenja su ponovno najveća kod GH $(97,93 \%)$ i GK $(93,39 \%)$ membrane. Za ostale ispitivane membrane smanjenja su od $56,35 \%$ do $86,77 \%$. Veći pad smanjenja intenziteta obojenja postignut s MW membranom (56,35\%) od PW $(69,05 \%)$ najvjerojatnije se može pripisati analitičkoj pogrešci s obzirom na to da je za membrane s većim porama postignuta viša efikasnost uklanjanja obojenja.
Tablica 2 - Rezultati obojenja i intenziteta obojenja TOV-a i UF permeata nakon $3 \mathrm{~h}$ obrade

Table 2 - Colour and colour intensity results of textile wastewater (TWW) and UF permeates after $3 \mathrm{~h}$ of treatment

\begin{tabular}{l|c|c|c|c}
\hline $\begin{array}{l}\text { Membrana } \\
\text { Membrane }\end{array}$ & \multicolumn{2}{|c|}{$\begin{array}{c}\text { Obojenje } \\
\text { Colour }\end{array}$} & \multicolumn{2}{c}{$\begin{array}{c}\text { Intenzitet obojenja } \\
\text { Colour intensity }\end{array}$} \\
\cline { 2 - 5 } & TOV & $3 \mathrm{~h}$ & \multicolumn{1}{c}{ TOV } & $3 \mathrm{~h}$ \\
\hline GH & 0,220 & 0,0059 & 93,50 & 1,93 \\
\hline GK & 0,234 & 0,0373 & 101,80 & 6,72 \\
\hline PT & 0,226 & 0,0511 & 107,50 & 14,21 \\
\hline PU & 0,156 & 0,0693 & 92,88 & 22,11 \\
\hline PW & 0,225 & 0,0749 & 77,39 & 33,78 \\
\hline MW & 0,231 & 0,0887 & 87,18 & 26,98 \\
\hline
\end{tabular}

Smanjenje obojenja prikazano na slikama 1 i 2 pokazuje velik utjecaj MWCO vrijednosti membrana na smanjenje obojenja i intenziteta obojenja. Tako su GH i GK membrane s MWCO od 2 i 3 kDa imale najveće faktore zadržavanja (> 90 \%). Porastom MWCO (od 5 do 50 kDa) membrana dolazi do pada smanjenja obojenja i intenziteta obojenja i takva ovisnost je u skladu s istraživanjem Uzala i sur. ${ }^{41}$ Strukture bojila upotrijebljene u proizvodnji su tajna proizvođača i njihove molekulske mase (500 do $700 \mathrm{~g} \mathrm{~mol}^{-1}$ ovisno o bojilu) manje su od pora GH i GK membrana. Međutim, visoko smanjenje obojenja pokazuje velik utjecaj matrice upotrijebljene realne otpadne vode (visoka mutnoća, električna provodnost, sadržaj koloidnih čestica i obojenje). ${ }^{42}$

Razlika ulazne otopine TOV-a i permeata nakon $3 \mathrm{~h}$ obrade za svaku ispitivanu membranu prikazana je na slici 5. Dakle, najbolje uklanjanje bojila dobiveno je s $\mathrm{GH}$ membranom s obzirom na to da je permeat jedini bez obojenja.

\subsection{Protok ispitivanih UF membrana}

Faktor zadržavanja i protok permeata dvije su glavne karakteristike kojima se definira performansa neke membrane. Stoga će u ovom poglavlju biti prikazani rezultati permeabilnosti i normaliziranog protoka ispitivanih UF membrana. S obzirom na to da su se eksperimenti za svaku testiranu membranu provodili pri različitim radnim tlakovima držeći se preporuka 
proizvođača, za tumačenje membranskih performansi uspoređena je permeabilnost vode (fluks podijeljen $s$ radnim tlakom). Na slici 4 prikazana je permeabilnost ispitivanih UF membrana za demineraliziranu vodu i za otpadnu vodu tijekom $3 \mathrm{~h}$ obrade. Permeabilnost membrane demineralizirane vode određena je nakon stabilizacije fluksa membrane. Sa slike 4 vidljivo je da je permeabilnost vode najmanja za GH membranu u iznosu od 4,01 I $\mathrm{m}^{-2} \mathrm{~h}^{-1}$ bar $^{-1}$, a najveća za MW membranu $\mathrm{u}$ iznosu od $130 \mathrm{I} \mathrm{m}^{-2} \mathrm{~h}^{-1} \mathrm{bar}^{-1}$. Dakle, permeabilnost raste $\mathrm{s}$ povećanjem MWCO membrana.

Obradom TOV-a s ispitivanim UF membranama dolazi do trenutnog pada permeabilnosti otopine. Najmanji pad po-

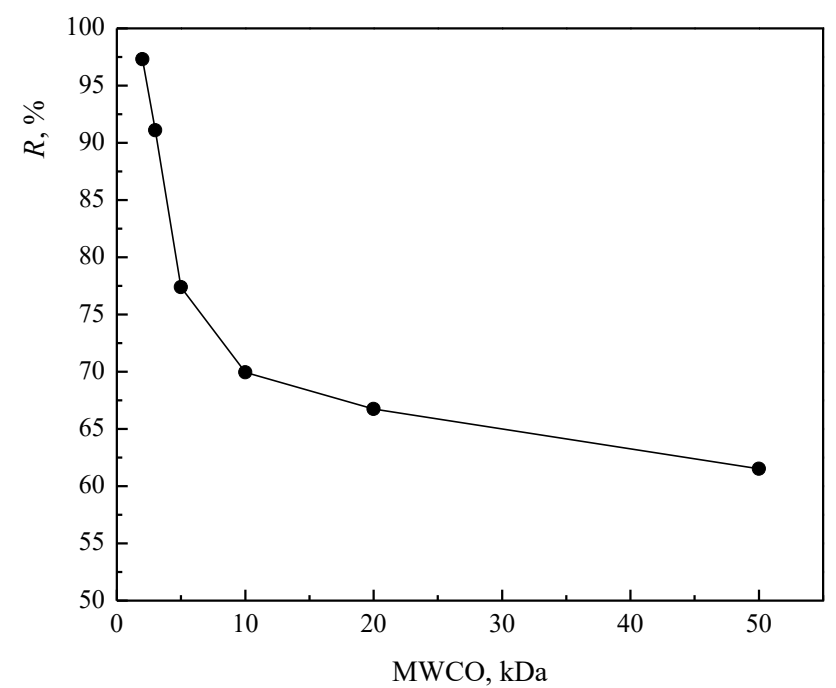

Slika 1 - Smanjenje obojenja u ovisnosti o MWCO membrana

Fig. 1 - Decrease in colour depending on MWCO for investigated membranes kazale su GK (24,8 \%) i GH (31,3\%) membrane s obzirom na to da one imaju najmanji MWCO. Daljnjim povećanjem vrijednosti MWCO od 5 do 50 kDa dolazi do sve većeg pada permeabilnosti u iznosu od 45,8 \% (PT), 53,0 \% (PU), 55,7 \% (PW) i 58,9 \% (MW). Uz početni pad vidljivo je da $\mathrm{GH}$ i GK membrane imaju blagi linearni pad permeabilnosti, dok sve ostale, pogotovo PU, PW i MW, imaju eksponencijalni pad u prvih 30 min obrade vode. Takav pad permeabilnosti ukazuje na izraženije blokiranje s povećanjem MWCO membrana. Blokiranje membrana može se prikazati normaliziranim protokom $\left(J / J_{0}\right)$ koji su prikazani na slici 5.

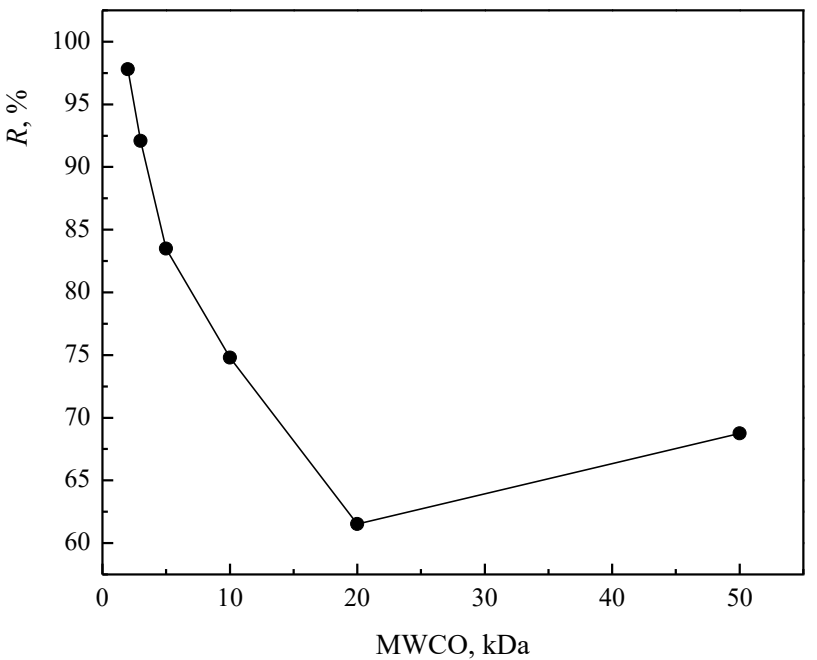

Slika 2 - Ovisnost smanjenja intenziteta obojenja o MWCO za ispitivane membrane

Fig. 2 - Dependence of colour intensity decrease on MWCO for investigated membranes

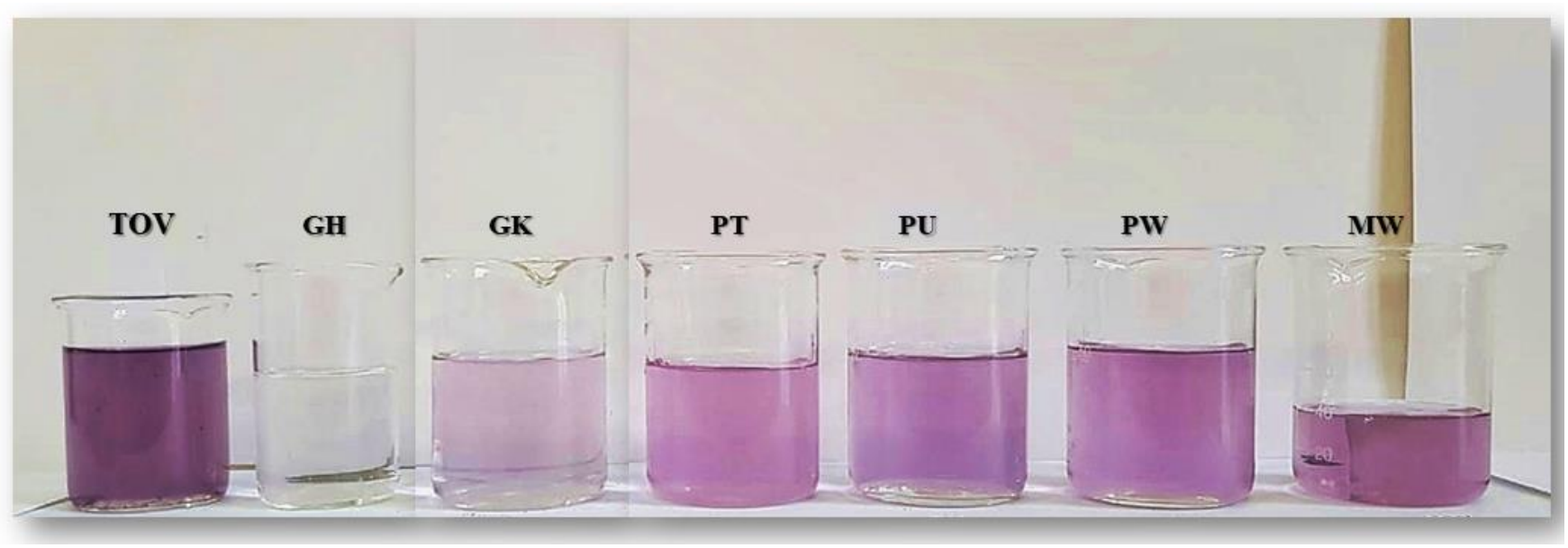

Slika 3 - Ovisnost smanjenja intenziteta obojenja o MWCO za ispitivane membrane

Fig. 3 - Dependence of colour intensity decrease on MWCO for investigated membranes 
Kao što se može vidjeti iz slike 5, GH i GK membrane pokazale su najmanje smanjenje normaliziranog fluksa, koje je bilo linearno i smanjilo se za oko $20 \%$ odnosno $10 \%$ u $3 \mathrm{~h}$ obrade. Ostale upotrijebljene membrane pokazuju eksponencijalni pad normaliziranog protoka potvrđujući intenzivnije blokiranje. Za PT, PU i MW membrane nagli pad fluksa kroz 15 min iznosio je otprilike $50 \%$, a za PW membranu $55 \%$. To se može pripisati većem MWCO, koji omogućuje veće nakupljanje suspendiranih čestica, otopljenih organskih i anorganskih čestica u membranskoj strukturi i uzrokuje veće blokiranje. ${ }^{43}$ Dobiveni rezultati pokazuju da je za membrane s najvećim MWCO dominantan mehanizam blokiranja stvaranjem kolača kao posljedica brzog blokiranja pora i adsorpcije na početku obrade. ${ }^{44}$

Membrane s manjim MWCO (2 i $3 \mathrm{kDa}$ ) uspješne su u uklanjanju obojenja i intenziteta obojenja. Međutim, s povećanjem MWCO dolazi do pada uklanjanja, ali i sve izraženijeg blokiranja. Daljnji tijek istraživanja uključit će pronalazak adekvatne predobrade u svrhu smanjenja blokiranja i povećanja uklanjanja obojenja.

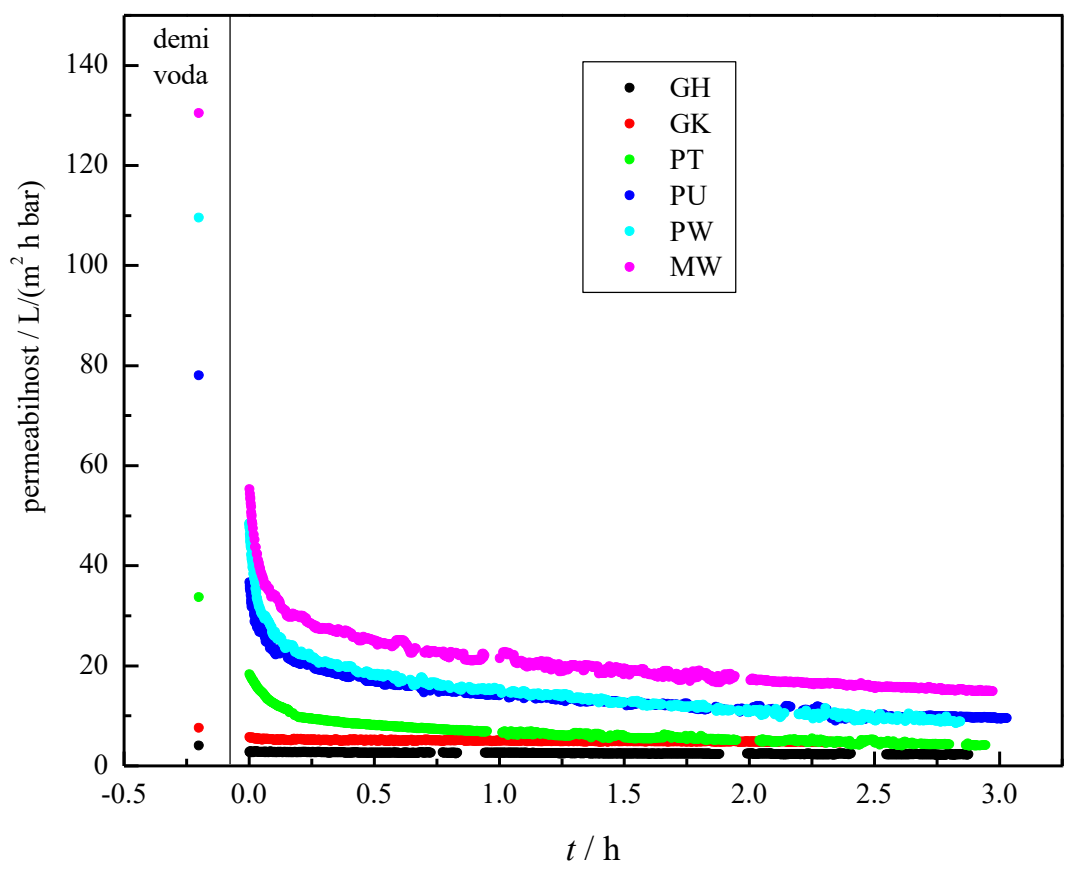

Slika 4 - Permeabilnost ispitivanih UF membrana

Fig. 4 - Permeability of investigated UF membranes

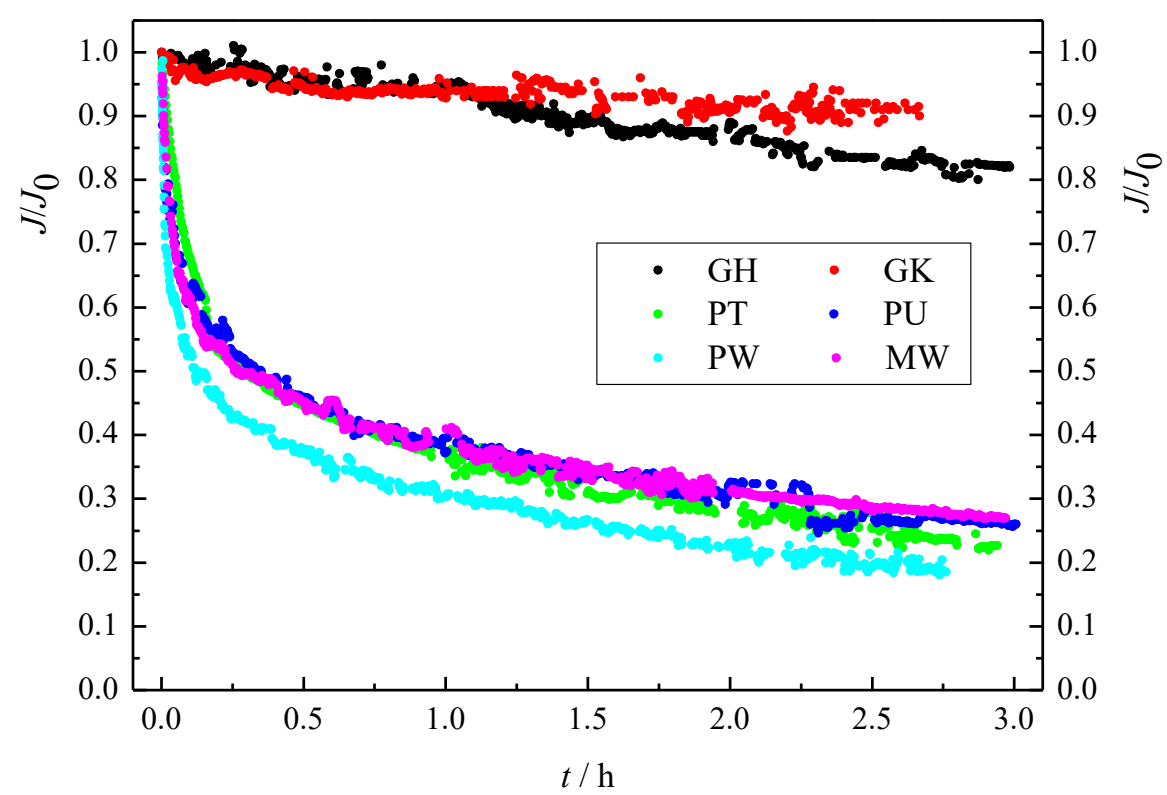

Slika 5 - Normalizirani protok otpadne vode za ispitivane UF membrane Fig. 5 - Normalized flux of wastewater for investigated UF membrane 


\section{Zaključak}

Testiranjem šest komercijalnih UF membrana ( $2-50 \mathrm{kDa})$ na TOV-i utvrđeno je smanjenje obojenja od $61,60 \%$ do $97,03 \%$ te intenziteta obojenja od $56,35 \%$ do $97,93 \%$. Najveće smanjenje obojenja i intenziteta obojenja dobiveno je s GH $(97,03$ i 97,93\%) i GK membranom $(84,05$ i $93,39 \%$ ), što se može pripisati njihovim manjim vrijednostima MWCO. Permeat dobiven $\mathrm{GH}$ membranom je bezbojan za razliku od permeata dobivenih GK i ostalim membranama. Permeabilnost i normalizirani protok pokazuju izraženije blokiranje s povećanjem MWCO membrana.

\section{Popis kratica i simbola \\ List of abbreviations and symbols}

\begin{tabular}{|c|c|}
\hline A & $\begin{array}{l}\text { - apsorbancija } \\
\text { - absorbance }\end{array}$ \\
\hline MWCO & $\begin{array}{l}\text { - granična molekulska masa, kDa } \\
\text { - molecular weight cut-off, kDa }\end{array}$ \\
\hline$p$ & $\begin{array}{l}\text { - radni tlak, bar } \\
\text { - working pressure, bar }\end{array}$ \\
\hline MF & $\begin{array}{l}\text { - mikrofiltracija } \\
\text { - microfiltration }\end{array}$ \\
\hline NF & $\begin{array}{l}\text { - nanofiltracija } \\
\text { - nanofiltration }\end{array}$ \\
\hline PA & $\begin{array}{l}\text { - poliamid } \\
\text { - polyamid }\end{array}$ \\
\hline PAN & $\begin{array}{l}\text { - poliakrilonitril } \\
\text { - polyacrylonitrile }\end{array}$ \\
\hline PES/PS & $\begin{array}{l}\text { - poli(eter-sulfon)/polisulfon } \\
\text { - poly(ether-sulfon)/polysulfone }\end{array}$ \\
\hline $\mathrm{R}$ & $\begin{array}{l}\text { - faktor zadržavanja } \\
\text { - retention factor }\end{array}$ \\
\hline RO & $\begin{array}{l}\text { - reverzna osmoza } \\
\text { - reverse osmosis }\end{array}$ \\
\hline TOV/TWW & $\begin{array}{l}\text { - tekstilna otpadna voda } \\
\text { - textile wastewater }\end{array}$ \\
\hline UF & $\begin{array}{l}\text { - ultrafiltracija } \\
\text { - ultrafiltration }\end{array}$ \\
\hline
\end{tabular}

\section{Literatura}

\section{References}

1. R. Padhye, R. Nayak, Acoustic textiles, Springer, 2016, doi: https://doi.org/10.1007/978-981-10-1476-5.

2. M. Barås, Assessing the environmental sustainability of an apparel supply chain: the development of a conceptual model based on a comparative study of preferred tools and actual practices, 2015.,
URL: https://www.semanticscholar.org/paper/Assessing-theenvironmental-sustainability-of-an-\%3A-

Bar\%C3\%A5s/c0ad927816ffb348e83db67007c02ebd5a6b9 $57 \mathrm{~d}$.

3. W. D. Schindler, P. J. Hauser, Chemical finishing of textiles, Elsevier, 2004, doi: https://doi.org/10.1201/9781439823477

4. L. Bokić, I. Rezić, Biological Purification of Waste Water of the Textile Industry, Tekstil 52 (2003) 631-639.

5. A. Raja, A. Arputharaj, S. Saxena, P. Patil, Water requirement and sustainability of textile processing industries, $\mathrm{u}$ : Water in Textiles and Fashion, Elsevier, 2019, str. 155-173, doi: https://doi.org/10.1016/B978-0-08-102633-5.00009-9.

6. G. T. Güyer, K. Nadeem, N. Dizge, Recycling of pad-batch washing textile wastewater through advanced oxidation processes and its reusability assessment for Turkish textile industry, J. Clean Prod. 139 (2016) 488-494, doi: https://doi.org/10.1016/j.jclepro.2016.08.009.

7. Y. W. Berkessa, B. Yan, T. Li, V. Jegatheesan, Y. Zhang, Treatment of anthraquinone dye textile wastewater using anaerobic dynamic membrane bioreactor: Performance and microbial dynamics, Chemosphere 238 (2020) 124539, doi: https://doi.org/10.1016/j.chemosphere.2019.124539.

8. M. Marcucci, I. Ciabatti, A. Matteucci, G. Vernaglione, Membrane technologies applied to textile wastewater treatment, Ann. N. Y. Acad. Sci. 984 (2003) 53-64, doi: https://doi.org/10.1111/j.1749-6632.2003.tb05992.x.

9. F. D. Chequer, G. A. R. de Oliveira, E. R. A. Ferraz, J. C. Cardoso, M. B. Zanoni, D. P. de Oliveira, Textile dyes: dyeing process and environmental impact, u: Eco-Friendly Textile Dyeing and Finishing, 2013. str. 151-176, doi: https://doi.org/10.5772/53659.

10. P. Schoeberl, M. Brik, R. Braun, W. Fuchs, Treatment and recycling of textile wastewater - case study and development of a recycling concept, Desalination 171 (2005) 173-183, doi: https://doi.org/10.1016/j.desal.2004.02.105.

11. G. Crini, E. Lichtfouse, Advantages and disadvantages of techniques used for wastewater treatment, Environ. Chem. Lett. 17 (2019) 145-155, doi: https://doi.org/10.1007/s10311-018-0785-9.

12. V. Srebrenkoska, S. Zhezhova, S. Risteski, S. Golomeova, Methods for wastewaters treatment in textile industry, International Scientific Conference, 21-22 November, 2014, Gabrovo.

13. Y. Wang, B. Y. Gao, Q. Y. Yue, J. C. Wei, W. Z. Zhou, R. Gu, Color Removal from Textile Industry Wastewater Using Composite Flocculants, Environ. Technol. 28 (2007) 629637, doi: https://doi.org/10.1080/09593332808618824.

14. K. Anastasakis, D. Kalderis, E. Diamadopoulos, Flocculation behavior of mallow and okra mucilage in treating wastewater, Desalination 249 (2009) 786-791, doi: https://doi.org/10.1016/j.desal.2008.09.013.

15.S. Shamsnejati, N. Chaibakhsh, A. R. Pendashteh, S. Hayeripour, Mucilaginous seed of Ocimum basilicum as a natural coagulant for textile wastewater treatment, Ind. Crops Prod. 69 (2015) 40-47, doi: https://doi.org/10.1016/j.indcrop.2015.01.045.

16. B.-Y. Gao, Y. Wang, Q.-Y. Yue, J.-C. Wei, Q. Li, Color removal from simulated dye water and actual textile wastewater using a composite coagulant prepared by polyferric chloride and polydimethyldiallylammonium chloride, Separat. Purif. Technol. 54 (2007) 157-163, doi: https://doi.org/10.1016/j.seppur.2006.08.026. 
17. K. Muda, A. Aris, M. R. Salim, Z. Ibrahim, A. Yahya, M. C. van Loosdrecht, A. Ahmad, M. Z. Nawahwi, Development of granular sludge for textile wastewater treatment, Water Res. 44 (2010) 4341-4350 doi: https://doi.org/10.1016/j.watres.2010.05.023.

18. A. Pala, E. Tokat, Color removal from cotton textile industry wastewater in an activated sludge system with various additives, Water Res. 36 (2002) 2920-2925, doi: https://doi.org/10.1016/S0043-1354(01)00529-2.

19. M. Işık, D. T. Sponza, Anaerobic/aerobic treatment of a simulated textile wastewater, Separat. Purif. Technol. 60 (2008) 64-72,

doi: https://doi.org/10.1016/j.seppur.2007.07.043.

20. I. K. Kapdan, S. Alparslan, Application of anaerobic-aerobic sequential treatment system to real textile wastewater for color and COD removal, Enzyme Microb. Technol. 36 (2005) 273-279, doi: https://doi.org/10.1016/j.enzmictec.2004.08.040.

21. A. Vlyssides, D. Papaioannou, M. Loizidoy, P. Karlis, A. Zorpas, Testing an electrochemical method for treatment of textile dye wastewater, Waste Manage. 20 (2000) 569-574, doi: https://doi.org/10.1016/S0956-053X(00)00028-3.

22. A. Vlyssides, M. Loizidou, P. Karlis, A. Zorpas, D. Papaioannou, Electrochemical oxidation of a textile dye wastewater using a $\mathrm{Pt} / \mathrm{Ti}$ electrode, J. Hazard. Mater. 70 (1999) 41-52, doi: https://doi.org/10.1016/S0304-3894(99)00130-2.

23. T. V. Ramachandra, N. Ahalya, R. D. Kanamadi, Biosorption: Techniques and Mechanisms, CES Technical Report 110 (2005).

24. E. A. Kumbasar, A. Korlu, Textile Wastewater Treatment, BoD-Books on Demand, 2016, doi: https://doi.org/10.5772/ 60627.

25. S. Sridhar, S. Moulik, Membrane Processes: Pervaporation, Vapor Permeation and Membrane Distillation for Industrial Scale Separations, John Wiley \& Sons, 2018, doi: https://doi.org/10.1002/9781119418399.

26. N. C. Cinperi, E. Ozturk, N. O. Yigit, M. Kitis, Treatment of woolen textile wastewater using membrane bioreactor, nanofiltration and reverse osmosis for reuse in production processes, J. Clean. Prod. 223 (2019) 837-848, doi: https://doi.org/10.1016/j.jclepro.2019.03.166.

27. S. Dutta, K. Nath, Feasibility of forward osmosis using ultra low pressure RO membrane and Glauber salt as draw solute for wastewater treatment, J. Environ. Chem. Eng. 6 (2018) 5635-5644, doi: https://doi.org/10.1016/j.jece.2018.08.037

28. M. F. Abid, M. A. Zablouk, A. M. Abid-Alameer, Experimental study of dye removal from industrial wastewater by membrane technologies of reverse osmosis and nanofiltration, Iran. J. Environ. Health Sci. Eng. 9 (2012) 17, doi: https://doi.org/10.1186/1735-2746-9-17.

29. M. Gholami, S. Nasseri, M.-R. Alizadehfard, A. Mesdaghinia, Textile dye removal by membrane technology and biological oxidation, Water Qual. Res. J. 38 (2003) 379-391, doi: https://doi.org/10.2166/wqrj.2003.024.

30.D. Zhao, S. Yu, A review of recent advance in fouling mitigation of NF/RO membranes in water treatment: pretreatment, membrane modification, and chemical cleaning, Desalination Water Treat. 55 (2015) 870-891, doi: https://doi.org/10.1080/19443994.2014.928804.

31.i. Uyanık, O. Özkan, i. Koyuncu, NF-RO membrane performance for treating the effluent of an organized industrial zone wastewater treatment plant: Effect of different UF types, Water 9 (2017) 506,

doi: https://doi.org/10.3390/w9070506.

32. J. Hoslett, T.M. Massara, S. Malamis, D. Ahmad, I. van den Boogaert, E. Katsou, B. Ahmad, H. Ghazal, S. Simons, L. Wrobel, Surface water filtration using granular media and membranes: A review, Sci. Total Environ. 639 (2018) 12681282, doi: https://doi.org/10.1016/j.scitotenv.2018.05.247.

33. C. Fersi, M. Dhahbi, Treatment of textile plant effluent by ultrafiltration and/or nanofiltration for water reuse, Desalination 222 (2008) 263-271, doi: https://doi.org/10.1016/j.desal.2007.01.171.

34. A. Aouni, C. Fersi, B. Cuartas-Uribe, A. Bes-Pía, M. I. AlcainaMiranda, M. Dhahbi, Reactive dyes rejection and textile effluent treatment study using ultrafiltration and nanofiltration processes, Desalination 297 (2012) 87-96, doi: https://doi.org/10.1016/j.desal.2012.04.022.

35. M. Berradi, A. Essamri, A. El Harfi, Discoloration of water loaded with vat dyes by the membrane process of ultrafiltration, J. Mater. Environ. Sci. 7 (2016) 1098-1106.

36. H. P. Srivastava, G. Arthanareeswaran, N. Anantharaman, V. M. Starov, Performance of modified poly (vinylidene fluoride) membrane for textile wastewater ultrafiltration, Desalination 282 (2011) 87-94, doi: https://doi.org/10.1016/j.desal.2011.05.054

37. C. Ratanatamskul, N. Kaweenantawong, Ultrafiltration as a clean technology for reclamation and reuse of wastewater from textile industry, u: Conf. Ninth International Conference of Greening of Industry Network, Bangkok, Sustainability at the Millennium: Globalization, Competitiveness and the Public Trust January, 2001., str. 21-25.

38. M. Berradi, A. El Harfi, Discoloration of charged models wastewater with reactive and dispersed dyes by the combined process of coagulation-ultrafiltration, J. Mater. Environ. Sci. 8 (2017) 1762-1769.

39. J. Dasgupta, M. Singh, J. Sikder, V. Padarthi, S. Chakraborty, S. Curcio, Response surface-optimized removal of Reactive Red 120 dye from its aqueous solutions using polyethyleneimine enhanced ultrafiltration, Ecotoxicol. Environ. Saf. 121 (2015) 271-278, doi: https://doi.org/10.1016/j.ecoenv.2014.12.041

40. M. Racar, K. Obajdin, D. Dolar, K. Košutić, Pretreatment for the reclamation of rendering plant secondary effluent with NF/RO: UF flat sheet versus UF hollow fiber membranes, Clean Technol. Environ. Policy 22 (2020) 399-408, doi: https://doi.org/10.1007/s10098-019-01789-8.

41. N. Uzal, L. Yilmaz, U. Yetis, Microfiltration/ultrafiltration as pretreatment for reclamation of rinsing waters of indigo dyeing, Desalination 240 (2009) 198-208, doi: https://doi.org/10.1016/j.desal.2007.10.092.

42. A. Hidalgo, M. Gomez, M. Murcia, M. Serrano, R. RodriguezSchmidt, P. Escudero, Behaviour of polysulfone ultrafiltration membrane for dyes removal, Water Sci. Technol. 77 (2018) 2093-2100, doi: https://doi.org/10.2166/wst.2018.124.

43. K. Košutić, D. Dolar, T. Strmecky, Treatment of landfill leachate by membrane processes of nanofiltration and reverse osmosis, Desalination Water Treat. 55 (2015) 2680-2689, doi: https://doi.org/10.1080/19443994.2014.939863.

44. M. Racar, D. Dolar, M. Farkaš, N. Milčić, A. Špehar, K. Košutić, Rendering plant wastewater reclamation by coagulation, sand filtration, and ultrafiltration, Chemosphere 227 (2019) 207215, doi: https://doi.org/10.1016/j.chemosphere.2019.04.045. 


\section{SUMMARY}

\section{Removal of Dyes from Textile Wastewater by Ultrafiltration Membranes

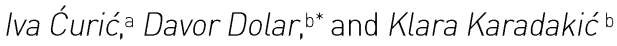

Wastewater from the textile industry belongs to the category of the most polluted industrial wastewaters and poses a special danger to the aquatic environment. The aim of this study was to examine the membrane retention efficiency of textile wastewater (TOV) with commercial ultrafiltration (UF) membranes (GH, GK, PT, PU, PW, MW) with a wide range of molecular weight cut-off (MWCO), 2-50 kDa. The tested UF membranes resulted in a reduction in colour and colour intensity from $56.35 \%$ to $97.93 \%$. Membrane of lower MWCO values (below $3 \mathrm{kDa}$ ) may be suitable for removing dyes from the real TOV sample.

\section{Keywords}

Textile industry, wastewater, ultrafiltration, colour, dyes

${ }^{a}$ Galeb Dalmatian Tricot d. d., Punta 6,

${ }^{b}$ University of Zagreb

Faculty of Chemical Engineering and Technology

Marulićev trg 19, HR-10 000 Zagreb

Republic of Croatia 